\title{
The Effectiveness of a Video-Based Laboratory on Discovery Learning to Enhance Learning Outcomes
}

\author{
Nur Fadlilah $^{1}$, Dwi Sulisworo ${ }^{2, *}$, Guntur Maruto ${ }^{3}$ \\ ${ }^{1}$ Department of Physics Education, Ahmad Dahlan University, Indonesia \\ ${ }^{2}$ Graduate School, Ahmad Dahlan University, Jalan Prof. Dr. Supomo, Indonesia \\ ${ }^{3}$ Department of Physics, Gadjah Mada University, Indonesia
}

Received May 6, 2020; Revised June 19, 2020; Accepted July 5, 2020

Copyright $\odot 2020$ by authors, all rights reserved. Authors agree that this article remains permanently open access under the terms of the Creative Commons Attribution License 4.0 International License

\begin{abstract}
Various advantages are offered by technology to improve the quality of learning, including physics learning. The use of technology in learning physics can make students more productive than the lecture method. This study aimed to determine the effectiveness of the use of video-based laboratory on the discovery learning model to enhance physics learning outcomes. The design used in this study was a nonequivalent pre-test and post-test control group design. The research used a purposive sampling technique to obtain two groups. One experimental group applied discovery learning with video-based laboratory and one control group applied conventional learning. The statistical analysis used was ANCOVA, with an error rate of $5 \%$. The results of the analysis show that there is an influence of discovery learning assisted with a video-based laboratory. In this study, it also appears that there is an interaction between learning models and learning styles. Students experiencing discovery learning with a video-based laboratory have higher learning outcomes than those experiencing a conventional one. In general, this research can contribute to the field of education, especially physics learning, to optimize the use of technology as a learning medium. This learning strategy allows students to participate directly in proving the concept of the material. Besides, this model can be active alternative learning in improving student learning outcomes.
\end{abstract}

Keywords Discovery Learning, Video-Based Laboratory, Learning Outcomes, Prior Knowledge, Learning Styles

\section{Introduction}

Physics is one of the most fundamental sciences of sciences [1]. However, the perspective that physics is complicated is the reason for the decline in students interest in physics [2]. One study group usually consists of students with different school backgrounds, thus different prior knowledge- Prior knowledge is known as the extent to which students already know the material.

In addition to prior knowledge, there are also differences in learning styles that are allegedly the cause of the different learning outcomes obtained. Learning styles are a source of cognitive styles, learning models, and response styles as the way one receives, absorbs, and stores information. According to learning models, it can be divided into visual, auditory, and kinesthetic learning styles. The learning style can determine the role of the senses in responding to learning in the classroom. According to [3], learning styles are various approaches or ways of learning. Most students tend to exhibit bad habits. Such as irregular learning, studying only when approaching an exam, do not have complete notes, and are not accustomed to making summaries. These habits make it more difficult for students to understand physics. This lack of learning behavior is likely caused by the teacher not paying attention to the learning styles of students in learning.

Learning activities with a discovery learning approach result in students being able to improve and enhance their skills and cognitive processes. This statement is following [4] that if involved continuously in learning discovery, students will be able to understand and develop cognitive aspects better. Discovery through experimentation also one of the methods often used to facilitate understanding. Still, in reality, this method encounters obstacles such as limited time, inadequate tools, and a lack of students' responses to problems encountered. In this case, it is necessary to use technology as a medium of learning physics.

Various advantages are offered by technology to improve the quality of physics learning. The use of technology in learning physics is more productive than the lecture and demonstration methods [5]. Technology can 
improve and develop the professional abilities of teachers, and can be used as a source of learning, as a tool for learning interactions, as well as a forum for learning. But in reality, both students and teachers have not been able to utilize technology as a learning medium. Technology is still used only as a means of communication and other social interactions. As a result, many students wasted study time. Many researches show that technology enables to improve students' knowledge and skills [6]

Various problems in learning affect the low learning outcomes of students. In a public school at Sikka, East Nusa Tenggara, physics learning outcomes are relatively low compared to other natural science subjects. This condition encouraged researchers to make reforms by optimizing the use of technology as a medium for learning physics. Through technology, the material will be presented using video about physical phenomena. The video will be recorded by students and is then analyzed using a tracker to obtain accurate data. The competences and knowledge of the student group taught using video and explained using a tracker have increased [7]. That way, it is expected that physics learning outcomes can be improved.

Considering the problems above, the researcher carried out research on the effectiveness of a video-based laboratory on the discovery learning model to enhance learning outcomes in terms of knowledge and learning styles.

\section{Theoretical Background}

\subsection{Discovery Learning}

Discovery learning is a fundamental inquiry approach [8]. The teaching method is inquiry-based and is considered a constructivist-based approach to education. A literature review shows that discovery learning occurs whenever students are not provided with the conceptual understanding and must find it independently and only with the material provided [9]. In the process of finding, students carry out a series of stages of learning from observing to organizing their findings into a concept of knowledge.

Discovery learning encourages students to be active agents in their learning processes [10]. Students are guided by the teacher who directs the question to the problem so that it allows students to draw simple relationships, generalizations, or conclusions [8]. The cognitive abilities of students using discovery learning models are better than those using conventional learning [11]. Based on research findings by [12], it was concluded that through discovery learning, student learning in cognitive, affective, and psychomotor aspects has improved.

\subsection{Video-based Laboratory}

The video-based laboratory is a practicum activity in a laboratory in the form of educational software based on video analysis [13]. The video-based laboratory is an objective analysis based learning media contained in a video. Video-Based Laboratory (VBL) helps researchers in analyzing physical phenomena quickly. Efficiently video-based laboratories can make students motivated to discover their physics concepts, and more eager to learn. This media can further familiarize students with carrying out scientific activities digitally. It also allows students to get closer to various phenomena that occur around them.

The results of [14] showed an increase in understanding of students that experienced learning processes implementing a video-based laboratory. The video analysis allows students to connect abstract physics concepts with real-life through innovative video modeling as it is an effective method for learning about free-fall motion [15]. It gives the opportunity to use this model to other physics phenomena (the inclined plane in this research)

\subsection{Learning Outcomes}

Changes in behavior mark learning outcomes. Although not all changes in behavior are made as the result of learning, learning activities are generally accompanied by changes in behavior [16]. Learning outcomes must be observable and supported by a type of test called a learning outcome test. Learning outcomes are the results obtained by students after learning activities [17]. Learning outcomes are also the success of the learning system. Learning outcomes are determined by the product and the process.

Based on the explanation above, as a summary, learning outcomes are the actual abilities possessed by students after learning. The forms are in the way of cognitive, affective, and psychomotor skills. In this study, learning outcomes are only limited to the cognitive domain, measured through the analysis of post-test test results. The test questions are in the form of the same breakdown questions as the pre-test questions. Students do this after treatment.

\subsection{Prior Knowledge}

New knowledge is what can be thought of as "packets of information" [18]. Prior knowledge is a collection of individual expertise and experience gained during their life journey and will be brought to a new learning experience [19]. Student's prior knowledge is a collection of information that can bridge the extent to which other understandings can be used [20]. Prior knowledge possessed by students is obtained through the ability of teachers to process the information stored [21]. The teacher needs to know the extent of the students' prior knowledge.

Prior knowledge of every student is different. Different individuals state different information according to their ways and present information differently in their memory based on their prior experience and expertise [21]. Student's prior knowledge plays an essential role in learning because it supports the ease of students in 
accepting and understanding a new material or concept in education. Student's prior knowledge influences performance, academic results, and speed of completing studies [22].

In this study, prior knowledge was measured through the analysis of the results of the pre-test. The test questions are in the form of problem descriptions given to students before the discovery learning model or the conventional learning model was applied. This action is intended so that researchers know the extent of students' prior knowledge about the material to be taught in both sample groups.

\section{Method}

\subsection{Research Model}

This study used a quasi-experimental design using a nonequivalent (pretest-posttest) control group design. There was a control group and an experimental group that was given different treatments. In the sample group, a pretest was conducted to determine the students' prior knowledge, then treatment, and, finally, the posttest to find out the student's learning outcomes after treatment.

Table 1. Research design

\begin{tabular}{|c|c|c|c|}
\hline Groups & Pre-test & Treatment & Post-test \\
\hline Experiment & $\mathrm{R}_{1}$ & $\mathrm{X}$ & $\mathrm{R}_{2}$ \\
\hline Control & $\mathrm{R}_{1}$ & $\mathrm{Y}$ & $\mathrm{R}_{2}$ \\
\hline
\end{tabular}

\subsection{Research Sample}

This research was conducted on eleventh-grade students of a senior high school in Sikka, East Nusa Tenggara, Indonesia. The sampling technique used was purposive sampling to find an experimental group and a control group of eleventh-grade students. Each group has 24 students as samples.

\subsection{Analysis Techniques}

Before testing the hypothesis, the prerequisite test is in the form of a normality test. This test used the Shapiro Wilk test and a homogeneity test using the Fisher test. After the prerequisite test, the hypothesis test was performed using the ANCOVA test.

\section{Results}

\subsection{Learning Activity Description}

This research examines the effectiveness of learning. There are three aspects of learning effectiveness i.e. learning activities, students' responses to learning, and learning outcomes. From the learning activities in the experimental group, this learning could run well following the stages of learning (structure).

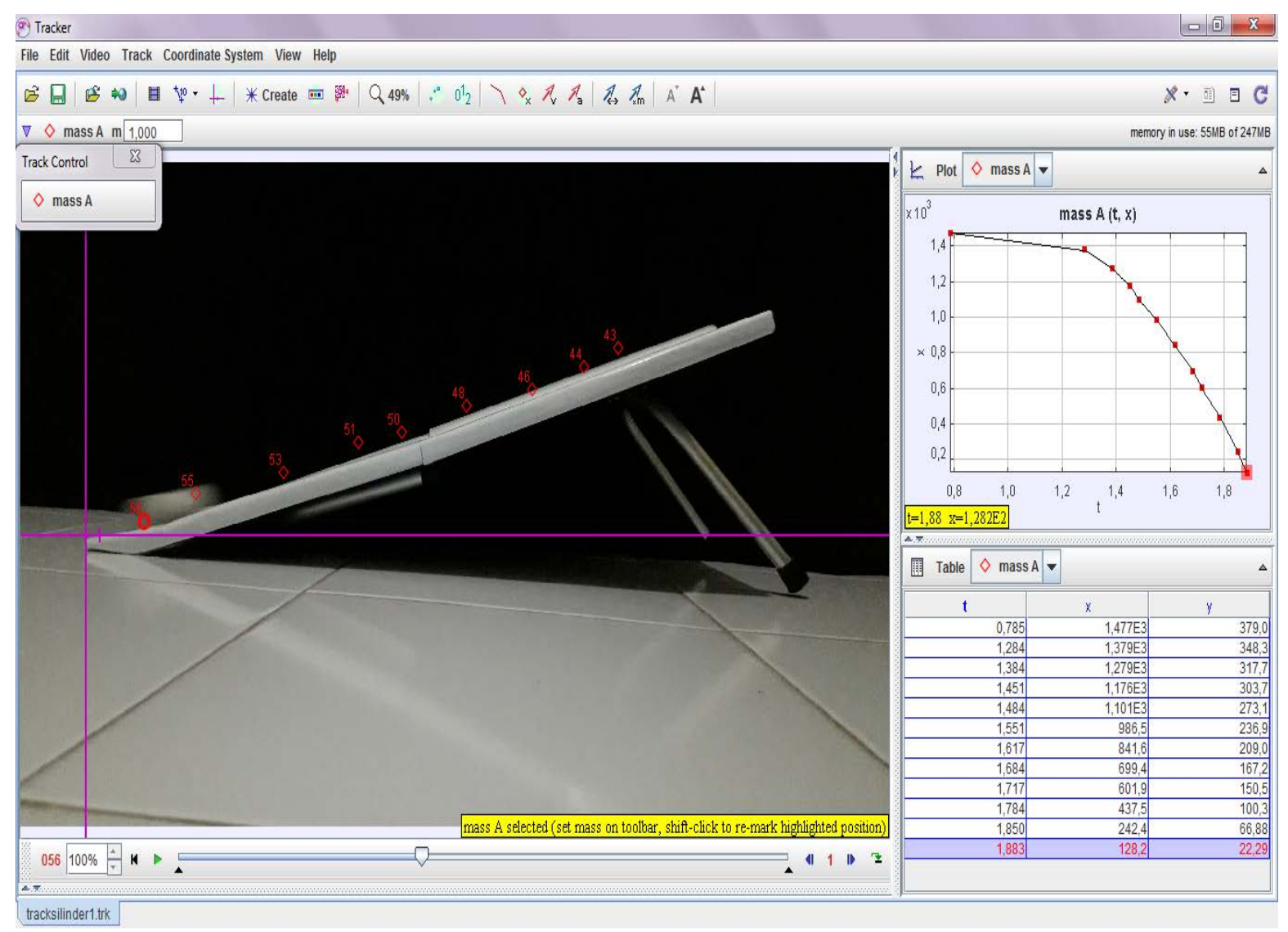

Figure 1. Learning activity using tracker application 
Under this structure, students in groups carried out the drawing in the form of video, then did tracking and analysis using the tracker application. The results of this analysis were used to solve the problems provided in the worksheet. Thus in terms of implementation, this model can be used. Figure 1 shows the learning activity using this application in the inclined plane as the main activity in this learning.

\subsection{Descriptive Analysis of Prior Knowledge}

Table 2 shows the results of the descriptive study of the prior knowledge of the experimental group and the control group.

In Table 2, it appears that the average value of the control group is higher than the experimental group-likewise, median, value mode, minimum, and maximum.

Table 2. Scores of prior knowledge

\begin{tabular}{|c|c|c|c|c|c|c|}
\hline Groups & $\mathrm{N}$ & Mean & Median & Modus & Min & Max \\
\hline Experiment & 24 & 19.1 & 20 & 20 & 8 & 28 \\
\hline Control & 24 & 19.4 & 20.5 & 13 & 9 & 29 \\
\hline
\end{tabular}

\subsection{Descriptive Analysis of Learning Styles}

Learning styles are various approaches or ways of learning [3]. A person's learning style is a combination of how a person absorbs, and then organizes and processes information [23]. From some of these descriptions, it can be said that learning styles are the way one receives, assimilates, and stores information.

Student learning styles include visual, auditory, or kinesthetic learning styles (V-A-K) [24]. The characteristics of these learning styles are visual students learning through what they see, auditory students learn through what they hear, and kinesthetic students learn through movement and touch. Although every student has a learning style (V-A-K), most students tend to have one dominant of the learning styles (V-A-K).

The results of the learning style study in the experimental group and the control group are then presented in the form of an average score of learning styles according to their characteristics as shown in Figure 2.

From Figure 2, it appears that in the experimental group the number of students with auditory learning styles is fewer than those with visual and kinesthetic learning styles. On the contrary, in the control group, the number of auditory students is higher than visual and kinesthetic.

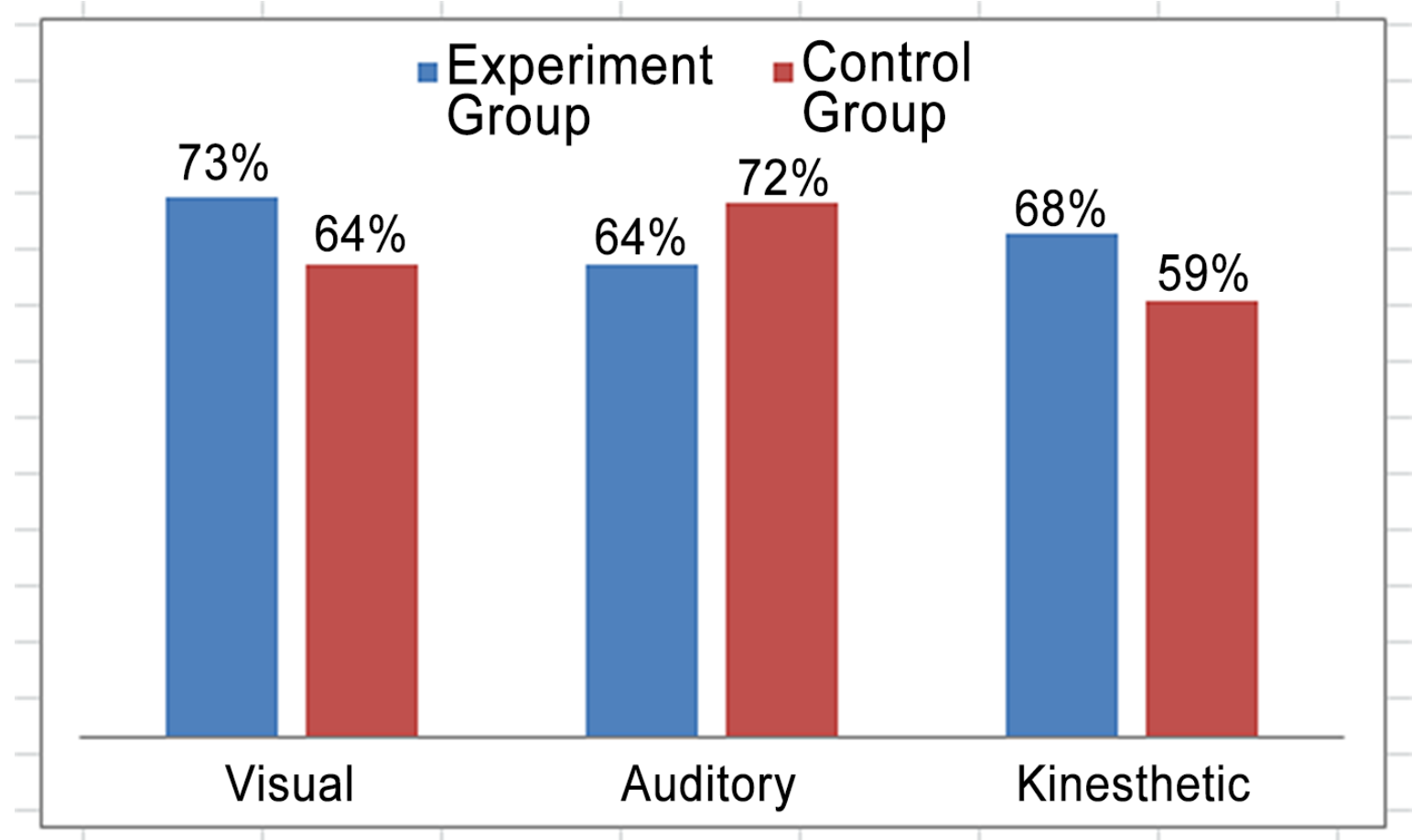

Figure 2. Average VAK learning style score 


\subsection{Descriptive Analysis of Learning Outcomes}

After the descriptive analysis of student learning outcomes in the experimental group and control group was complete, the average value, median, mode, minimum score, and maximum score were then calculated. Table 3 shows Description of learning outcomes data.

Table 3. Learning outcome scores

\begin{tabular}{|c|c|c|c|c|c|c|}
\hline Groups & N & Mean & Median & Modus & Min & Max \\
\hline Experiment & 24 & 76 & 78.5 & 57 & 57 & 89 \\
\hline Control & 24 & 66 & 68.5 & 59 & 35 & 86 \\
\hline
\end{tabular}

Table 3 shows that the average value of the learning outcomes of the control group is lower than that of the experimental group.

\subsection{Analysis of Covariance}

In this study, ANCOVA test used a three-variable covariance analysis technique using SPSS 23.0. Table 4 presents the results of the covariance analysis.

Table 4. ANCOVA results

\begin{tabular}{|c|c|c|c|c|c|}
\hline Source & $\begin{array}{c}\text { Type III Sum } \\
\text { of Squares }\end{array}$ & df & $\begin{array}{c}\text { Mean } \\
\text { Square }\end{array}$ & F & Sig. \\
\hline Corrected Model & $2247.640^{\mathrm{a}}$ & 3 & 749.213 & 6.242 & .001 \\
\hline Intercept & 50.019 & 1 & 50.019 & .417 & .522 \\
\hline Prior Knowledge & 38.926 & 1 & 38.926 & .324 & .572 \\
\hline Learning Style & 996.627 & 1 & 996.627 & 8.303 & .006 \\
\hline Learning Model & 750.283 & 1 & 750.283 & 6.251 & .016 \\
\hline Error & 5281.173 & 44 & 120.027 & & \\
\hline Total & 249071.000 & 48 & & & \\
\hline Corrected Total & 7528.813 & 47 & & & \\
\hline
\end{tabular}

a. R Squared $=.299$ (Adjusted R Squared $=.251$ )

Based on the analysis results shown in Table $4, \mathrm{df} 1=3$ and df $2=47$. The value of F-table $=2.80$ is obtained at a significance level of $5 \%$.

\subsection{Analysis of Learning Effectiveness}

There are several responses observed during learning. In this learning, there was a high level of student enthusiasm, both when studying in groups and during the process of making videos. Students could share roles to achieve learning goals. They qualitatively seemed at the level of collaboration, learning activity, and group discussion processes. From these aspects, learning with this model is responded positively to learning behavior and motivation.

The test of improving learning outcomes is viewed from the difference of $\mathrm{N}$-gain between the pre-test score and the post-test score in the experimental group and the control group. Data on the results of the two groups are in the medium classification; the experimental group at 0.7 and the control group 0.5. Next, an effect size analysis was performed to obtain information about the magnitude of the effect of a variable on other variables, the significance of the difference, and the relationship free from the influence of the sample size. The results of data calculations obtained an effect size value of 0.74 with a moderate interpretation. Besides using N-gain analysis and effect size, classical learning completeness analysis was also used by calculating the percentage of students who reach the Minimum Mastery Criteria (MMC). The mastery rate of learning outcomes of students in the experimental group was $62.5 \%$, and in the control group was $25 \%$.

\section{Discussion}

The students' prior knowledge determines the readiness of students in learning. Prior knowledge is the knowledge that students have before participating in the lesson. Prior knowledge becomes critical for teachers to know before starting learning. Through prior knowledge, the teacher can know the extent to which students already know the material. Students who have high prior knowledge tend to have better understanding compared to students who have a low one. In this study, both the experimental group and the control group have the same prior knowledge background, which can be understood by the similar average value of the prior knowledge; the experimental group is 19.1 and the control group is 19.4. Thus, in this study, it can be said that prior knowledge does not have much effect on improving student learning outcomes.

Furthermore, based on the results of the ANCOVA test, it was found that there was an influence of learning styles on students' physics learning outcomes. This result can be explained through the F-value of 8.30 , which is higher than the F-table of 2.80. Learning styles are the key to developing performance and achievement. In other words, learning styles can improve student physics learning outcomes.

Learners are accustomed to being taught from elementary to secondary schools with an auditory model. This model tends only to involve the senses of hearing. As a result, most learners are accustomed to using auditory learning styles. In this study, the average value of auditory student learning outcomes in the experimental group is lower than other learning styles. In the control group, the average score of auditory students tends to be higher than the visual and kinesthetic. Students with visual learning styles in the experimental group get a higher percentage of scores than those in the control group. This result is obtained because they are easier to remember what is seen than what is heard.

Similarly, students with kinesthetic learning styles show significant differences in learning outcomes between the experimental group and the control group. This finding is because the characteristics of the kinesthetic learning style 
require individuals to touch something that provides information to remember it. They like to experiment with the material obtained. In other words, a video-based laboratory assisted discovery learning model can facilitate visual and kinesthetic learners according to their characteristics.

The effectiveness of the discovery learning model assisted by the video-based laboratory is explained from $\mathrm{N}$-gain test, effect size, and MMC values. The analysis shows that the $\mathrm{N}$-gain of the experimental group of 0.7 is higher than that of the control group of 0.5. Furthermore, the effect size value of 0.74 is obtained with the interpretation of the moderate effect on the variable studied and strengthened by the learning outcomes of students in the experimental group by $62.5 \%$ reaching passing grade. It means that learning using a discovery learning model assisted by a video-based laboratory is more effective. This model can improve physics learning outcomes in the material of balance and dynamics of rotation compared to learning with conventional models.

The reason is that a series of learning activities with the discovery learning model actively involve students in the learning process. In line with [4] that if involving continuously in learning discovery, students will understand and be able to develop cognitive aspects better. Several other studies in various fields also show that the use of video for laboratory activities can improve learning outcomes. In the medical field, this method is used with a somewhat different learning strategy, namely the student-centered learning approach, more generally, while this study used discovery learning. However, using similar media (video-based laboratory) shows an increase in learning outcomes [25]. Likewise the study of chemistry obtained relatively similar results [26]. In similar studies in the field of physics education, VBL based on Matlab was used for kinematics problems [27]. The results of this study show an increase in student learning outcomes after participating in learning with this VBL. The use of VBL also shows the possibility of increasing understanding [28, 29]. In more general, the use of technology to enhance learning will improve students' learning performance $[6$, 30].

One of the reasons for the increase in learning outcomes with VBL is because students feel attracted to VBL as hands-on learning based on technology [31]. This result can be seen from the measurement of the level of student satisfaction with VBL. The findings of other researchers are in line with the results in this study, where VBL can increase MMC which includes understanding concepts and some other skills.

\section{Conclusions}

Based on the results of hypothesis testing, it is concluded that the discovery learning model assisted by the video-based laboratory is more effective in physics learning than the conventional one. This strategy can improve student learning outcomes better compared to conventional learning models.

\section{REFERENCES}

[1] H. D. Young, R. A. Freedman and L. Ford. Sears and Zemansky's University Physics With Modern Physics, Addison-Wesley, US, 2008.

[2] S.Y. Erinosho. How do Students Perceive the Difficulty of Physics in Secondary School? An Exploratory Study in Nigeria, International Journal for Cross-Disciplinary Subjects in Education, Vol.3, No.3, 1510-1515, 2013.

[3] Rahmani \& Jahanbakhsh. Learning Styles and Academic Achievement: a Case Study of Iranian High School Girls' Students, Procedia-Social and Behavioral Sciences, Vol.51, No.1, 1030-1034, 2012.

[4] B. Suryobroto. Proses Belajar Mengajar di Sekolah, Rineka Cipta, Jakarta, 2009.

[5] F. Noah. HighTech Tools for Teaching Physics: The Physics Education Technology Project, MERLOT Journal of Online Learning and Teaching, Vol.2, No.3, 109-121, 2006.

[6] S. Ardianti, D. Sulisworo, Y. Pramudya and W. Raharjo. The impact of the use of STEM education approach on the blended learning to improve student's critical thinking skills. Universal Journal of Educational Research, Vol. 8, No. 3B, 24-32, 2020.

[7] P. Hockicko, B. Trpisova and J. Ondrus. Correcting Students' Misconceptions About Automobile Braking Distances and Video Analysis Using Interactive Program Tracker, Journal of science education and technology, Vol.23, No.6, 763-776, 2017.

[8] J. B. Gregorio. Using Video Analysis, Microcomputer-Based Laboratories (MBL's) and Educational Simulations as Pedagogical Tools in Revolutionizing Inquiry Science Teaching and Learning, K12 STEM Education. Vol.1, No.1, 43-64, 2015.

[9] G. Singaravelu. Discovery Learning Strategies in English, Journal on English Language Teaching, Vol.2, No.1, 57-62, 2012.

[10] H. Gijlers and T.D. Jong. The Relation between Prior Knowledge and Students' Collaborative Discovery Learning Processes, Journal of Research in Science Teaching, Vol.42, No.3, 264-282, 2005.

[11] T. Martaida, N. Bukit and E. M. Ginting. The Effect of Discovery Learning Model on Student's Critical Thinking and Cognitive Ability in Junior High School, IOSR Journal of Research \& Method in Education (IOSR-JRME). Vol.7, No.6, 01-08, 2017.

[12] F. S. Resmawati, Prabowo, and Munasir. The Discovery Learning Model with A Scientific Approach to Increase Science Learning Achievement of Students, Advances in Intelligent Systems Research (AISR), Vol.157, No.1, 
198-200, 2018.

[13] Yulkifli, dan Ramli. The Use of Tracker Application to Enchance Physics Teachers in Senior High School in Making Laboratory Video, Pelita Eksakta, Vol.1, No.1, 31-36, 2018.

[14] E. Koleza and J. Pappas. The Effect of Motion Analysis Activities in a Video-Based Laboratory in Students' Understanding of Position, Velocity and Frames of Reference, International Journal of Mathematical Education in Science and Technology, Vol.39, No.6, 15-25, 2008.

[15] L. K. Wee, K. K. Tan, T.K, Leong and C. Tan. Using Tracker to Understand 'Toss Up' and Free Fall Motion: a Case Study, IOP Physics Education, Vol.5, No.4, 436-442, 2015.

[16] Aunurrahman. Belajar and Pembelajaran, Alfabeta, Bandung, 2014.

[17] S.B. Djamarah and A. Zain. Strategi Belajar Mengajar, PT Asdi Mahastya, Jakarta, 2006.

[18] R. J. Marzano. Building Background Knowledge for Academic Achievement, ASCD, USA, 2004.

[19] Liliasari and H. Rahmatan. Pengetahuan Awal Calon Guru Biologi Tentang Konsep Katabolisme Karbohidrat (Respirasi Seluler), Jurnal Pendidikan IPA Indonesia, Vol.1, No.1, 91-99, 2012.

[20] D. Fiser and N. Frey. Background Knowledge: The Overlooked Factor in Reading Comprehension, McGraw Hill, Network, 2013.

[21] D. Hu. The Effect of Scaffolding on The Performance of Students in Computer - Based Concept Linking and Retention of Comprehension. Dessertation, Submitted to The Faculty of Virginia Polytechnic Institude and State University Blacksburg, Virginia, 2006.

[22] T. Hailikari. Assesing University Students' Prior Knowledge, Implications for Theory and Practice, University of Helsinki Departement of Education Research Report 227, Helsinki, 2009.

[23] B. DePorter and H. Mike. Quantum Learning:
Membiasakan Belajar Nyaman dan Menyenangkan, Kaifa, Bandung, 2010.

[24] L. Aronne, C. Nagle, J. L. Styers, A. Combs and J. A. George. The Effects of Video-Based Pre-Lab Instruction on College Students' Attitudes and Achievement in the Digital Era. Electronic Journal of Science Education, Vol. 23, No. 5, 3-21, 2019.

[25] S. L. Wakode and N. S. Wakode. Enhancement of Student Centered Learning using Video Based Practical Demonstration in First Year Medical Undergraduates. Journal of Clinical \& Diagnostic Research, Vol. 12, No. 7, 2018.

[26] L. S. Nadelson, J. Scaggs, C. Sheffield and O. M. McDougal. Integration of video-based demonstrations to prepare students for the organic chemistry laboratory. Journal of Science Education and Technology, Vol. 24, No. 4, 476-483, 2015 .

[27] M. U. Hassan and M. S. Anwar. 'PhysTrack': a Matlab based environment for video tracking of kinematics in the physics laboratory. European Journal of Physics, Vol. 38, No. 4, 045007, 2017.

[28] E. Koleza and J. Pappas. The effect of motion analysis activities in a video-based laboratory in students' understanding of position, velocity and frames of reference. International Journal of Mathematical Education in Science and Technology, Vol. 39, No. 6, 701-723, 2008.

[29] L. Trudel and A. Métioui. Effect of a video-based laboratory on the high school pupils' understanding of constant speed motion. International Journal of Advanced Computer Science and Applications,Vol. 5, No. 3, 2012.

[30] I. A. D. Astuti, D. Sulisworo and T. Firdaus. What is the student response to using the weblogs for learning resources? Journal of Physics: Conference Series, Vol. 1157, No. 3, art. no. $032012,2019$.

[31] G. G. Arslan, D. Ozden, G. Goktuna and C. Ayik. A study on the satisfaction of students for the time spent watching video-based learning during their basic nursing skills' training. International Journal of Caring Sciences, Vol. 11, No. 1, 427-436, 2018. 